\title{
A PARTICIPAÇÃO DE UMA CRIANÇA COM SÍNDROME DE DOWN EM PRÁTICAS PEDAGÓGICAS NA EDUCAÇÃO INFANTIL
}

\author{
LA PARTICIPACIÓN DE UN NIÑO CON SÍNDROME DE DOWN EN LAS \\ PRÁCTICAS PEDAGÓGICAS DE LA EDUCACIÓN INFANTIL
}

\section{THE PARTICIPATION OF A PUPIL WITH DOWN SYNDROME IN PEDAGOGICAL PRACTICES IN CHILD EDUCATION}

\author{
Jáima Pinheiro de OLIVEIRA ${ }^{1}$ \\ Mariane Andreuzzi ARAUJO ${ }^{2}$
}

RESUMO: A fase pré-escolar faz parte de um período decisivo na formação de uma criança. Nesse contexto, essa pesquisa teve como objetivo analisar situações de mediação e práticas pedagógicas que interferiram de maneira positiva junto ao acesso curricular e à interação social de uma criança com Síndrome de Down. Uma turma de pré-escola, sua professora e uma cuidadora da criança-alvo participaram dessa pesquisa. Os dados foram obtidos por meio de observação sistemática e registrados com filmagens e notas de campo. Os resultados indicaram mediações favoráveis ao acesso curricular nas seguintes situações: proximidade entre a criança e a professora; compartilhamento de atividades com a criança; pedidos de colaboração da criança em atividades de rotina; proposição de atividades em grupo; dentre outras. Concluímos que a qualidade de interação e a preocupação com essa qualidade foram os principais fatores responsáveis pela promoção da participação da criança-alvo nas atividades.

PALAVRAS-CHAVE: Educação infantil. Práticas pedagógicas. Inclusão.

RESUMEN: La fase preescolar forma parte de un período decisivo en la formación de un niño. En ese contexto, esta investigación tuvo como objetivo analizar las situaciones de mediación y las prácticas pedagógicas que interfirieron de manera positiva, junto al acceso curricular e interacción social de un niño con síndrome de Down. Participaron de esta investigación una clase preescolar, su profesora y su cuidadora. Los datos fueron obtenidos por medio de observación sistemática y fueron registrados con filmaciones y notas de campo. Los resultados indicaron que existen mediaciones favorables al acceso curricular en las siguientes situaciones: proximidad entre el niño y la profesora; intercambio en las actividades con el niño; solicitudes de colaboración del niño en las actividades de rutina; propuesta de actividades en grupo; entre otras. Concluimos que la calidad de interacción y

\footnotetext{
${ }^{1}$ Universidade Estadual Paulista (UNESP), Marília - SP - Brasil. Docente do Departamento de Educação Especial e do Programa de Pós-graduação em Educação da Faculdade de Filosofia e Ciências (FFC). ORCID: <https://orcid.org/0000-0002-0156-3804>.E-mail: jaima@marilia.unesp.br

${ }^{2}$ Universidade Estadual Paulista (UNESP), Marília - SP - Brasil. Discente do Programa de Pós-graduação em Educação da Faculdade de Filosofia e Ciências (FFC). Foi bolsista do Conselho Nacional de Desenvolvimento Científico e Tecnológico $(\mathrm{CNPq})$ durante parte do período de realização dessa pesquisa. ORCID: <https://orcid.org/0000-0003-0193-7981>. E-mail: marianearaujo90@yahoo.com.br
} 
su preocupación fueron los principales factores responsables para la motivación de la participación del niño en las actividades planteadas.

PALABRAS CLAVE: Educación infantil. Prácticas pedagógicas. Inclusión.

ABSTRACT: Pre-school is part of a decisive period in the formation of a child. In this context, this research aimed to analyze mediation situations and pedagogical practices that interfered in a positive way with curricular access and social interaction of a child with Down syndrome. A preschool class, her teacher, and a caregiver of the target child participated in this research. The data collection was conducing through systematic observation and recorded with filming and field notes. The results indicated favorable mediations for curricular access in the following situations: proximity between the child and the teacher; sharing of activities with the child; requests for collaboration of the child in routine activities; proposition of group activities; among others. We conclude that the quality of interaction and the concern with this quality were the main factors responsible for promoting the participation of the target child in the activities.

KEY WORDS: Child education. Pedagogical practices. Inclusion.

\section{Introdução}

As transformações socioculturais e sociopolíticas, dentre outras, têm gerado grandes demandas para o aperfeiçoamento de políticas públicas de atendimento à criança pequena. A Educação Infantil tornou-se etapa obrigatória a partir da alteração na Lei de Diretrizes e Bases da Educação Nacional (BRASIL, 1996), por meio da Lei $n^{\circ}$. 12.796, de quatro de abril de 2013 (BRASIL, 2013). Os municípios e os estados tinham até o ano de 2016 para garantir a inclusão das crianças de quatro anos na escola pública e, atualmente, ainda há muito que se fazer, tanto em relação a estes aspectos formais de acesso quanto à estruturação, às percepções e ao funcionamento dessa etapa educacional obrigatória.

Ainda são observadas muitas confusões entre as funções de cuidar e educar nesse contexto, muito embora seja consenso sobre a fundamental articulação e presença delas na Educação Infantil. As dificuldades instaladas ao longo de décadas ainda remetem a uma ideia mais voltada ao assistencialismo, ao cuidado. No entanto, devemos reiterar que essas duas funções não podem ser dissociadas e o que importa é o respeito em relação à infância, enquanto construção social e histórica de uma fase peculiar da vida de todos os sujeitos.

Vigotsky foi o primeiro psicólogo moderno a sugerir que a cultura fosse considerada como um dos fatores principais, senão o essencial, para a constituição do sujeito. Por isso, esse teórico concebeu as funções psicológicas superiores não apenas como um produto de 
atividade cerebral, mas, fundamentalmente, influenciadas por aspectos socioculturais. Essa complexidade, atrelada ao desenvolvimento da linguagem, seria o fio condutor da formação humana (VIGOTSKY, 1994). Com isso, Vigotsky tentou explicar essa formação a partir da interação entre aspectos biológicos, históricos e sociais.

Os fatores socioculturais são de tamanha importância para este teórico, que mesmo considerando um aspecto particular de um indivíduo, temos que pensar que a sua construção ocorreu a partir da relação desse indivíduo com seus pares (VIGOSTKY, 1997). Nessa perspectiva interacionista, surgiram, também, as maiores contribuições de Vigotsky para os aspectos da aprendizagem. Para este autor, todo o processo de desenvolvimento humano depende da aprendizagem. Aprendizagem aqui entendida como a internalização de conceitos promovidos por essas interações (aprendizagens) sociais. Desse modo, podemos inferir que, ainda que uma criança não tenha riscos biológicos para o seu desenvolvimento, ou outra alteração específica que o impeça, a participação em ambientes e práticas sociais específicas é que poderá proporcionar essa aprendizagem.

Nesse contexto, citamos a escola, que deve conceber a criança como um ser ativo que pode articular as suas ações à representação de mundo que constitui sua cultura (VIGOSTKY, 1997; 1994). Para Ghiraldelli (1996), Montaigne e Rousseau constituíram a base da construção moderna de infância, tida como “[...] uma época especial de cada ser humano". (p. 17). E, por mais que tenha avançado essa concepção, é somente no século XIX que são observadas práticas pedagógicas diferenciadas nas escolas. Algumas dessas instituições começaram a utilizar jogos, por exemplo, como meio de favorecer o processo de aprendizagem. Esse uso de jogos parece ser um dos indicadores dessa concepção diferenciada de infância, na qual essa fase passa a ser vista como um período singular do desenvolvimento infantil (CHINALIA, 2009).

Por outro lado, hoje, vivenciamos um período no qual a produção e o consumo de conceitos sobre a infância interferem diretamente no comportamento não só das crianças, mas dos adolescentes, jovens e adultos. Segundo Jobim e Souza (2001), essas novas concepções "[...] modelam formas de ser e agir de acordo com as expectativas criadas nos discursos que passam a circular entre as pessoas". (p. 29). Essas concepções, por sua vez, estão atreladas aos interesses culturais, políticos e econômicos do contexto social do qual estamos participando (JOBIM; SOUZA, 2001).

Kramer (2006) alerta para a necessidade de compreendermos que crianças, jovens e adultos são sujeitos da história e da cultura, além de serem por elas produzidos. Por isso, ao se 
falar em Educação Infantil, é preciso considerar os milhões de crianças brasileiras de 0 a 6 anos como crianças. Para essa autora, isso implica conceber aspectos pedagógicos em sua dimensão cultural, como conhecimento, arte e vida, e não só como algo instrucional, que objetiva ensinar coisas.

Nesse sentido, vemos que a estrutura escolar exige dos professores a criação de condições para que cada criança se aproprie das atividades escolares no seu sentido subjetivo e na sua significação social, não apenas como um receptáculo do saber, mas sim como agente do seu próprio desenvolvimento. No entanto, nota-se que tais exigências, em muitos casos, vão muito além das possibilidades de atuação e de formação destes profissionais, principalmente quando eles se deparam com a diversidade (DRAGO; DIAS, 2017; MIRANDA et al., 2013).

Ao se falar em diversidade, é inevitável a discussão mais específica sobre a inclusão escolar, no tocante às crianças com deficiência. Assim como, é ainda mais inevitável considerar o quanto essa discussão caminha a passos lentos em relação à Educação Infantil. Nesse contexto, muitos pesquisadores reiteram sobre as inúmeras contribuições desse processo para todas as crianças, tendo em vista o respeito à diferença e o reconhecimento da diversidade, a necessidade de se pensar em construção e implementação de recursos e estratégias pedagógicas que considerem estes aspectos e, fundamentalmente, a construção de uma rede de apoio (SOUZA; AMORIM; ARAUJO, 2017; SANINI; BACKES; BOSA, 2015, DRAGO; DIAS, 2017; OLIVEIRA et al., 2017).

Nessa perspectiva, discussões sobre como ocorre o processo de inclusão na Educação Infantil, como organizar as atividades, quais as alternativas para a diminuição das barreiras educacionais para que o aluno com deficiência tenha acesso ao conteúdo curricular são importantes, já que elas auxiliam na concretização dos objetivos propostos por este trabalho de forma a contemplar a criança pequena como um sujeito de direitos (MIRANDA et al., 2013).

A partir dessas ponderações, abordaremos aqui aspectos que envolvem a problemática de compreensão de quais práticas pedagógicas podem ser realizadas na Educação Infantil para contribuir com o acesso curricular de crianças com Síndrome de Down. Considerando que a fase pré-escolar faz parte desse período decisivo na formação da criança e que, portanto, é sobretudo nessa fase que devemos planejar e mediar as situações capazes de contribuir positivamente para o desenvolvimento da criança, essa pesquisa teve como objetivo analisar 
situações de mediação e práticas pedagógicas que interferiram de maneira positiva junto ao acesso curricular e à interação social de uma criança com Síndrome de Down.

\section{Aspectos Metodológicos}

Essa pesquisa $^{3}$ foi realizada em uma Escola Municipal de Educação Infantil (EMEI) da rede municipal de ensino de uma cidade do interior do estado de São Paulo. Participaram desta pesquisa uma turma de pré-escolares e suas respectivas professoras e cuidadoras. $\mathrm{O}$ principal critério de seleção dessa turma foi o de ter uma criança com Síndrome de Down matriculada e a participação voluntária da escola, das professoras, das cuidadoras e dos responsáveis pelas demais crianças da turma.

Tendo em vista a obrigatoriedade da Educação Infantil para crianças com quatro e cinco anos de idade (BRASIL, 2013), optou-se pela seleção de escolares nesta faixa-etária, que no município no qual foi realizada a pesquisa, frequentavam as etapas denominadas de Nível I e Nível II.

Para as finalidades dessa pesquisa, serão denominados de A (Criança-alvo da pesquisa), P (Professora) e C (Cuidadora) os atores que aparecem como alvo nos registros e discussões dos dados obtidos. Estes são os focos de caracterização e contextualização em relação ao ambiente no qual ocorreu a coleta de dados dessa pesquisa. A é uma criança do sexo feminino, com quatro anos de idade (à época da coleta), que cursava o Nível I no período vespertino. Essa criança frequentava instituição escolar desde o primeiro ano de vida e possuía três atendimentos especializados, a saber: Terapia Ocupacional, Fonoaudiologia e Fisioterapia; P possuía 43 anos de idade, graduação em Pedagogia, Especialização em Educação Infantil e 17 anos de experiência em Educação Infantil; C tinha 33 anos de idade, Ensino Médio completo e um ano e três meses de experiência em Educação Infantil.

Sobre a coleta de dados, ela ocorreu na escola, contemplando atividades dentro e fora da sala de aula. Foram realizadas oito sessões de observação, registradas com filmadora e anotações de campo (VIANNA, 2003). Em seguida, foram efetuadas transcrições do material filmado, contemplando ambientes, ações, comportamentos, mediações pedagógicas e falas dos participantes. Essas transcrições compuseram um banco de dados para posterior análise, a partir de uma categorização por eixos temáticos. O critério para o início de registro era o de

\footnotetext{
${ }^{3}$ Essa pesquisa respeitou todas as normas estabelecidas pela Resolução 466/2012, referentes aos aspectos éticos em pesquisas com seres humanos e foi realizada após a aprovação pelo Comitê de Ética em Pesquisa da Universidade Estadual Paulista (UNESP).
} 
que ele fosse iniciado no momento em que a professora começasse uma atividade e o término seria o momento no qual a criança finalizasse essa atividade proposta.

A escolha dos dias de observação levou em consideração o planejamento semanal da professora, para que fossem contempladas diferentes atividades desse planejamento, tais como: lendas folclóricas, brincadeiras livres, jogos, atividades livres com materiais distintos, contação de histórias, pintura em azulejos com guache e outras brincadeiras fora da sala de aula.

A análise de dados foi realizada a partir do estabelecimento de eixos temáticos, com base em Bardin (2011). Nesse entendimento, “[...] as categorias são rubricas ou classes, as quais reúnem um grupo de elementos (unidades de registro, no caso da análise de conteúdo) sob um título genérico, agrupamento esse efetuado em razão dos caracteres comuns destes elementos" (BARDIN, 2011, p. 117). Nesse caso, essa análise levou em consideração a indicação de eixos temáticos para agrupamento dos dados que pudessem subsidiar a busca de respostas pelos objetivos principais dessa pesquisa, por isso, optamos pela pré-definição desses eixos temáticos, sem desconsiderar, por sua vez, a indicação natural dos dados obtidos. Com base nos objetivos da pesquisa foram estabelecidos eixos que indicassem a presença de: "mediações pedagógicas envolvendo a organização de espaço e tempo"; "mediações pedagógicas com uso de estratégias de comunicação"; "mediações pedagógicas com foco para brincadeiras".

Esses eixos foram considerados em momentos de interação entre A com a sua professora, entre A e seus colegas e entre A e outros atores de interação, de tal modo que pudéssemos vislumbrar momentos de mediações positivas nesses contextos. Os dados obtidos foram discutidos à luz da literatura especializada.

\section{Resultados e Discussão}

A seguir, apresentaremos alguns excertos de transcrições que indicam situações nas quais foi possível observar exemplos de mediações pedagógicas de um planejamento de atividades com organização do espaço, do tempo, de materiais e, fundamentalmente, com estratégias que contemplavam o uso da comunicação e, consequentemente da interação. Os relatos foram indicados por situações ocorridas dentro e fora de sala de aula, de tal modo que seus conteúdos pudessem ser descritos e analisados de forma mais ampla. 
Figura 1 - Exemplos de situações nas quais foi possível apreender momentos de "mediações pedagógicas" que envolviam a organização de espaço, materiais, tempo, estratégias de comunicação e brincadeiras

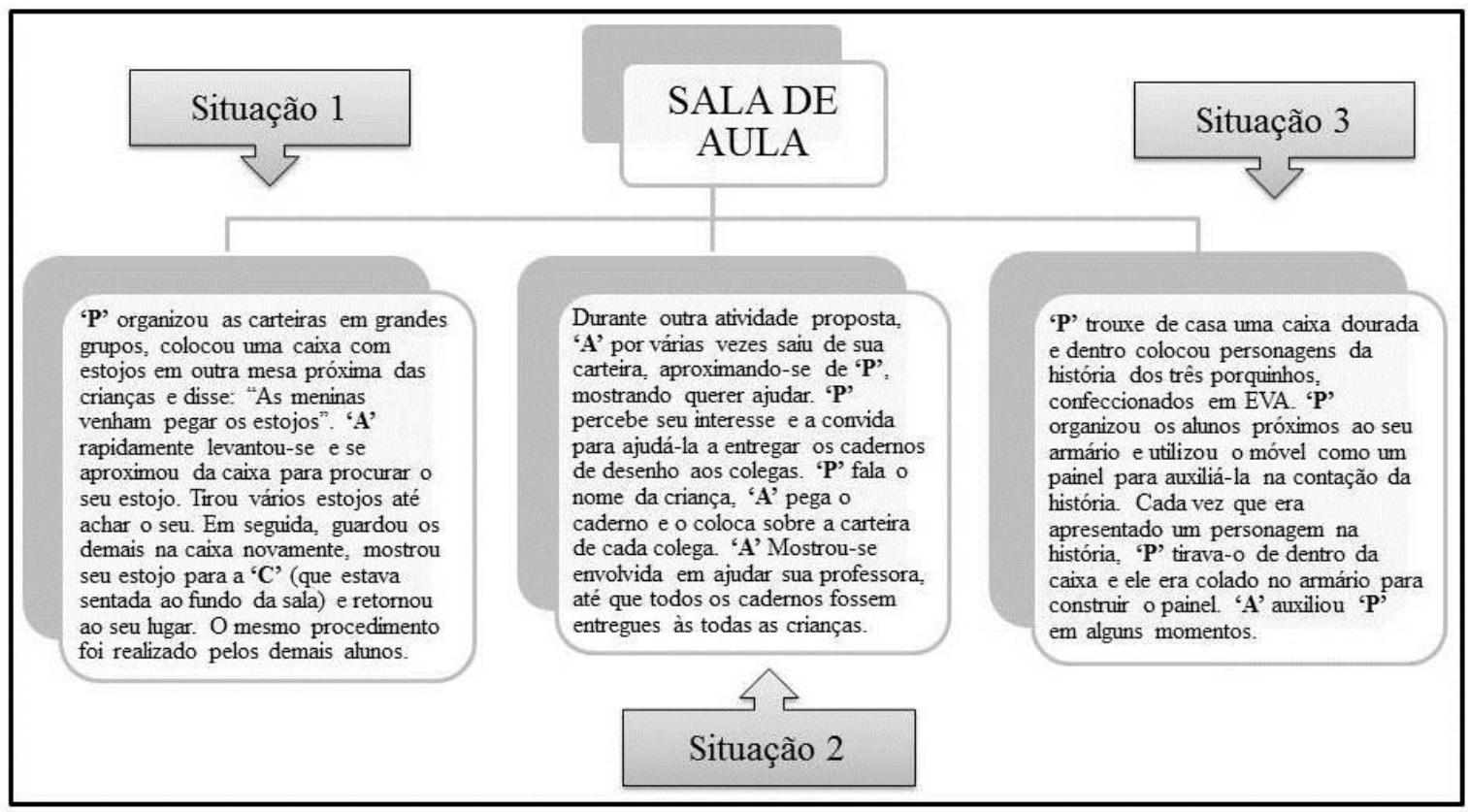

Fonte: Elaboração própria

Na Figura 1, é possível observar que 'P' adotou diferentes formas de organização dos ambientes, das crianças, do tempo e da disposição dos materiais para que as atividades acontecessem. Em alguns momentos é possível inferir, também, que essa organização antecedeu a chegada dos alunos à escola e buscou, a todo instante, a participação de A.

Essa organização é um aspecto fundamental para práticas pedagógicas nos ambientes da Educação Infantil, já que cada atividade requer um planejamento e ações intencionais do professor que estabeleçam formas adequadas de lidar com o espaço e o tempo, de tal modo que permita que as crianças explorem esses ambientes por um tempo adequado. Essa rotina pode ainda ser decisiva para incentivar relações positivas da criança com o ambiente escolar, favorecendo a criação artística, a manipulação dos objetos, a elaboração de desenhos, de dramatizações e de outras atividades essenciais ao desenvolvimento infantil (CHAVES, 2015).

Faria e Sales (2007) destacam que essas práticas favorecem o desenvolvimento da noção de tempo, o envolvimento em atividades corporais, imaginativas, o contato com o saber cultural, a apropriação da linguagem oral e escrita, a produção de novos conhecimentos e vivência de situações colaborativas entre professor/criança e criança/criança. 
Um dos trechos aqui expostos (situação 2) exemplifica o posicionamento da professora quanto à busca pela participação e pela colaboração de ' $A$ ' na distribuição dos materiais dos colegas, simulando uma situação de interação numa atividade de rotina. Essas ações sugerem uma visão de criança ativa, com múltiplas possibilidades de desenvolvimento humano, mediadas pelo outro, e permitem dar vez e voz às crianças pequenas, além de situálas no contexto escolar, valorizando suas contribuições e potencialidades, ao mostrar que elas são parte deste grupo (LIMA; RIBEIRO; VALIENGO, 2012).

Figura 2 - Exemplos de situações nas quais foi possível apreender momentos de "mediações pedagógicas" que envolviam a organização de espaço, materiais, tempo, estratégias de comunicação e brincadeiras

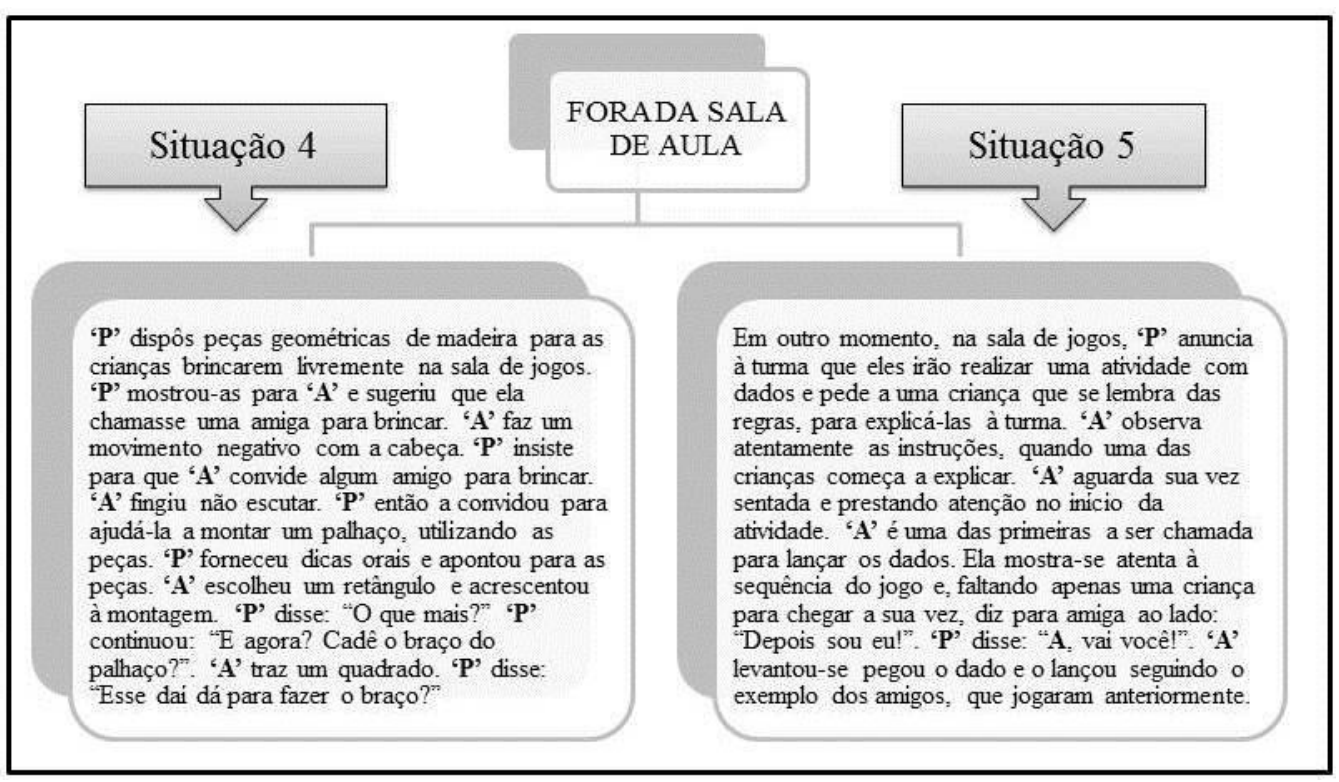

Fonte: Elaboração própria

Durante a atividade de brincadeira com peças geométricas (situação 4), observa-se que ' $\mathrm{P}$ ' convida 'A', sugerindo a montagem de um palhaço. 'P' explica quais ações podem ser realizadas, oferece apoio à criança durante todo o processo de realização do brinquedo. Além disso, 'P' procura também resgatar com a criança o que foi produzido, instigando a criança a buscar novas possibilidades (por exemplo, substituindo um triângulo por um quadrado para que o braço do palhaço ficasse 'melhor').

$\mathrm{Na}$ atividade envolvendo o dado (situação 5), percebe-se que 'P' faz uso de um jogo e de um material concreto como estratégia para auxiliar as crianças na apropriação do conceito de números. Nessa atividade, ao identificar o número do dado jogado, as crianças deveriam pegar palitos em número correspondente àquele que aparecia no dado. 
Fontes et al., (2009) comentam que os materiais concretos podem ser ricos em possibilidades de ensino ${ }^{4}$ e atuam como facilitadores em situações em que seja necessária a explicação de novos conceitos e conteúdos. Da mesma maneira, o jogo pode ser usado como uma importante estratégia para que as crianças sintam-se motivadas a participar da atividade e se apropriar dos conteúdos curriculares, em meio a atitudes de convívio social, como respeitar a vez e as ações do outro. Desenvolvem, também, aspectos referentes ao desenvolvimento moral, a partir da apreensão das regras do jogo.

Figura 3 - exemplos de situações nas quais foi possível apreender momentos de “mediações pedagógicas" que envolviam a organização de espaço, materiais, tempo, estratégias de comunicação e brincadeiras

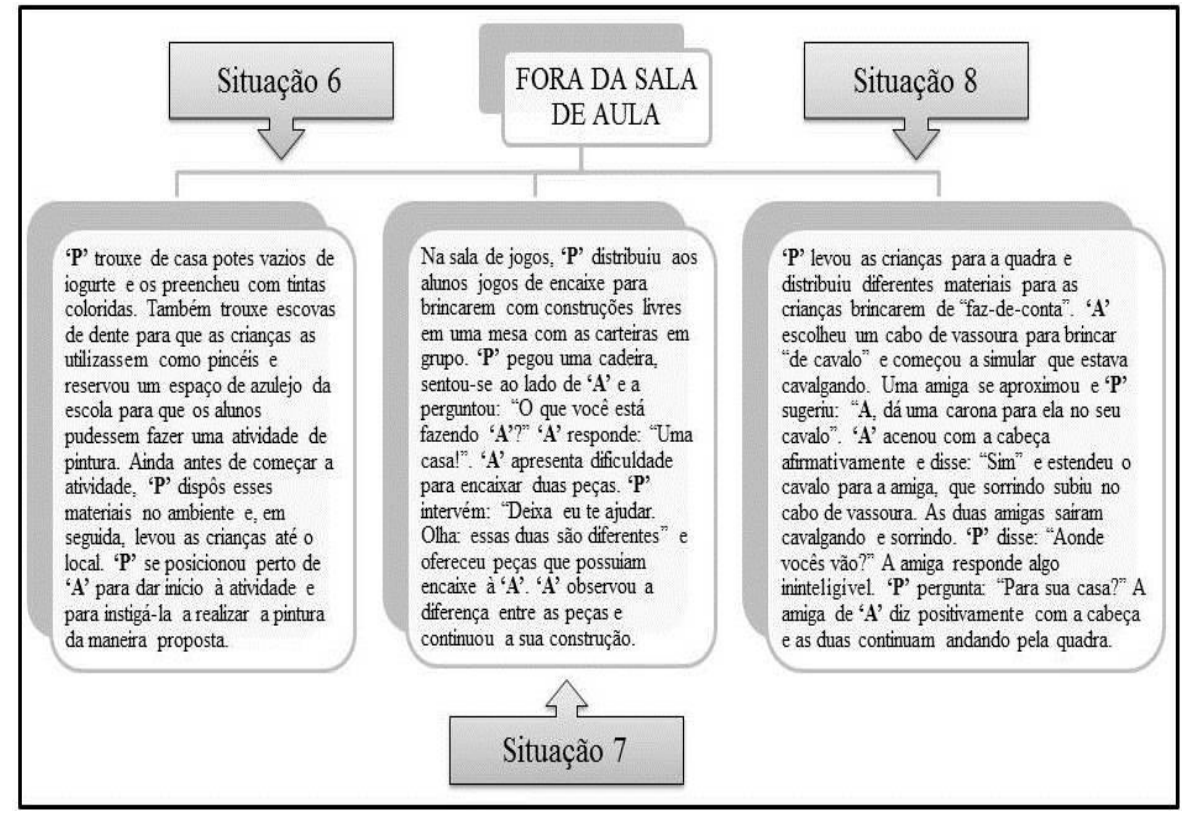

Fonte: Elaboração própria

Nos últimos exemplos, observa-se o oferecimento de materiais e a participação ativa de 'P' para que as construções livres (situação 7) e as brincadeiras de faz-de-conta (situação 8) acontecessem, também, com mediações dela. Ao questionar ' $A$ ' sobre a carona, sobre "aonde estavam indo", 'P' solicitou e forneceu oportunidades para que outras crianças brincassem juntas e acompanhassem o desenvolvimento da ação de 'A'. 'P' enriquece o contexto da brincadeira. Estas práticas vão ao encontro das ideias de Lazaretti (2016) ao

\footnotetext{
${ }^{4}$ Excepcionalmente esse termo foi utilizado aqui, respeitando-se a percepção dos autores, mas reitera-se que as autoras desse artigo ora apresentado mantêm um posicionamento de não atribuir às atividades da Educação Infantil um caráter de ensino, tendo em vista que o conceito de educação é mais amplo e mais voltado às questões culturais de tempo e espaço.
} 
afirmar que as brincadeiras de faz-de-conta podem ser potencializadas por diferentes estratégias do professor, tais como: dispor materiais diversificados e sugerir novos enredos, que levem em conta o contexto e o ambiente no qual a brincadeira acontece, entre outras ações pedagógicas intencionais.

Chaves et al., (2015) reforçam a importância dos procedimentos didáticos serem intencionais e planejados de forma sistemática. Complementam, ainda, os autores, sobre a necessidade de o professor explicar ou expor às crianças os objetivos da atividade e para quê irão desenvolvê-la, pois são ensinamentos essenciais para que a criança pequena comece a compreender a função e a necessidade do planejamento e da organização prévia da ação pretendida.

Ainda, na situação 8 , a diversidade de materiais oferecidos às crianças é um dos aspectos importantes para uma atuação dinâmica na Educação Infantil e contribui para tornar o ambiente escolar mais rico em conhecimento cultural. Por outro lado, é necessário que esses materiais sejam pensados e sistematicamente organizados, de forma a contemplar os objetivos do planejamento pedagógico, já que a disposição dos materiais por si só, sem mediação pedagógica, não garante a apropriação de conhecimento e o desenvolvimento infantil (FARIA; SALES, 2007).

É importante destacar que as mediações observadas nas ações de 'P' estão presentes em todas as situações, garantindo, assim, que 'A' se envolvesse nas atividades. E, ainda, nas situações nas quais não foi possível estabelecer interação com pares, ' $\mathrm{P}$ ' procurou intensificar a sua interação com 'A'.

Aranha (2000) e Oliveira (2011) destacam a importância dessas mediações que garantem a concentração e a permanência da criança nas atividades, primeiramente com apoios, até que a criança seja capaz de realizar atividades semelhantes de forma autônoma. Ao compartilhar ações com a criança, ao fazer junto, ao encorajá-la, o sentimento de segurança se sobrepõe às dificuldades, as ações da criança são valorizadas e com ajuda do outro a criança se compreende como capaz.

Nessa direção, o professor não deve contentar-se com as situações postas. De alguma forma ou, em alguma medida, ele deve intervir, seja para incentivar a realização de uma atividade, seja para potencializar essa ação já iniciada. Foi possível observar esse posicionamento nas atitudes de 'P'. Assim, os objetivos alcançados e aqueles que ainda não atingidos devem orientar a escolha de novas estratégias, mediações e adaptações, para garantir a plena participação e o êxito na realização das atividades propostas no âmbito escolar. 
Os dados indicam que as atividades e vivências proporcionadas por ' $\mathrm{P}$ ' estiveram relacionados aos principais objetivos da Educação Infantil, pois permitiram, em grande medida, que 'A' participasse de atividades lúdicas, desenvolvesse aspectos de sua autonomia, ampliasse a interação dialógica com seus pares, estabelecesse vínculos afetivos e produzisse conhecimento, de forma geral. Tais práticas indicam o alcance da constituição de uma escola com perspectiva inclusiva (MIRANDA et al., 2009) ou com qualidade de interação, já que essa parece ser uma das mais fundamentais características que tornam as atividades satisfatórias.

\section{Considerações finais}

Consideramos e reiteramos que a fase pré-escolar é um dos períodos decisivos na formação da criança, e que é sobretudo nessa fase que devemos planejar e mediar situações capazes de contribuir com o desenvolvimento dessa criança. Com isso, objetivamos nessa pesquisa analisar situações de mediação e práticas pedagógicas que interferiram de maneira positiva junto ao acesso curricular e à interação social de uma criança com Síndrome de Down.

Os resultados obtidos ilustraram a participação da criança nas mais distintas atividades propostas pela professora e indicaram o envolvimento e interações dialógicas entre essa criança e seus pares, bem como posicionamentos ativos frente aos contextos vivenciados. Os dados permitiram considerar, também, que houve uma preocupação da professora em planejar com antecedência atividades que demonstraram organização do tempo, do espaço e de materiais, fundamentais para o sucesso de interações entre a professora e as crianças e entre as crianças e seus pares. Consideramos, portanto, que o nosso objetivo de pesquisa foi atingido.

De maneira pontual, foi possível concluir que as interações da criança-alvo foram mais favoráveis quando a professora estava atenta e se planejava, nas seguintes situações: fornecimento de explicações sobre o que seria realizado; oferecimento de materiais necessários para realizar a atividade proposta; auxílio físico necessário para que a criança pudesse desenvolver a atividade; comunicação e interação de modo a resgatar o que foi realizado pela criança.

Os dados indicaram, também, que nem sempre essa atenção ou preocupação da professora era planejada de maneira sistematizada, pois foi possível observar situações de rotina com ações simples que favoreciam uma interação com qualidade, por exemplo, quando 
eram utilizadas as seguintes estratégias pedagógicas: posicionar a criança próxima à professora; chamar a atenção da criança no momento de uma explicação; oferecer instruções orais coletivas e individuais; compartilhar a atividade com a criança; sentar-se perto da criança; posicionar ou organizar os materiais ao alcance de todas as crianças; inserir a criança em grupos de brincadeiras; brincar com as crianças; agrupar as carteiras de uma maneira que facilitasse a comunicação entre as crianças; solicitar a cooperação de outras crianças para prestar apoios, durante todos os momentos.

Destaca-se, ainda, como consideração, que a criança-alvo de discussão não somente estava em todas as atividades, mas era, fundamentalmente, parte delas. Precisamos, no entanto, alertar para o fato de que algumas características individuais de 'A' podem ter sido importantes e decisivas para essa participação, tais como: ' $A$ ' não possui nenhuma dificuldade de comunicação, mostrou traços de autonomia ao se impor em algumas situações (a exemplo de quando 'P' sugeriu interação com um colega e ela manteve-se isolada, até que ' $\mathrm{P}$ ' começasse a interagir com ela), usa gestos convencionalmente no contexto social em que vive e marca seu lugar neste espaço. Essas características são apontadas por alguns autores como metas a serem conquistadas nas interações com crianças que possuem deficiência intelectual, pois são fundamentais para ampliar e qualificar uma interação. Além disso, aspectos de estimulação essencial ou precoce possuem influência muito importante nesse desenvolvimento.

Por fim, consideramos e reiteramos que o planejamento sistematizado contribuiu, sobremaneira, para essa participação satisfatória de ' $A$ ' nas atividades propostas. Disso, podemos inferir e confirmar que os recursos, ainda que sejam adaptados, não são os principais responsáveis pelas práticas inclusivas. É o seu uso que indicará a sua função e, portanto, não basta apenas organizar o meio se a qualidade de interação com esse meio não for provisionada. Os dados aqui obtidos confirmam que é a preocupação com essa qualidade a principal responsável pela promoção da participação de 'A' nas atividades.

Sugerimos continuidade das análises em turmas diferentes e em escolas diferentes, para aperfeiçoamento dos aspectos metodológicos, assim como para a proposição de intervenção em ambientes escolares da Educação Infantil que mostrem uma sistematização desses dados como forma de favorecer a interação das crianças e, consequentemente, seu processo de desenvolvimento infantil. 
AGRADECIMENTOS: Ao Conselho Nacional de Desenvolvimento Científico e Tecnológico $(\mathrm{CNPq})$ pela bolsa concedida à segunda autora, durante parte do período de realização dessa pesquisa.

\section{REFERÊNCIAS}

ARANHA, M. S. Projeto Escola Viva - garantindo o acesso e permanência de todos os alunos na escola - alunos com necessidades educacionais especiais. Adequações Curriculares de Pequeno Porte. Brasília: MEC/SEEP, 2000.

BARDIN, L. Análise de conteúdo. Trad: L. de A. Rego \& A. Pinheiro. Lisboa: Edições 70, 2011.

BRASIL. Lei no 9.394, de 20 de dezembro de 1996. Estabelece as diretrizes e bases da educação nacional. Brasília, DF, 1996. Disponível em:

http://www.planalto.gov.br/ccivil_03/Leis/L9394.htm. Acesso em: 29 fev. 2018.

BRASIL. Lei $\mathbf{n}^{\mathbf{0}}$ 12.796, de 4 de abril de 2013. Altera a Lei $\mathrm{n}^{\circ}$ 9.394, de 20 de dezembro de 1996, que estabelece as diretrizes e bases da educação nacional, para dispor sobre a formação dos profissionais da educação e dar outras providências. Disponível em:

http://download.uol.com.br/educacao/do_5abril2013_pagina1.pdf. Acesso em: 12 ago. 2018.

CHAVES, M. Práticas pedagógicas na Educação Infantil: contribuições da Teoria HistóricoCultural. Fractal, Revista Psicologia, v. 27, n. 1, p. 56-60, 2015.

DRAGO, R.; DIAS, I. R. O bebê com Síndrome de Down na Educação Infantil: um estudo de caso. Revista Educação Especial, Santa Maria, v. 30, n. 58, p. 515-528, 2017.

FARIA, V. L. B.; SALLES, F. R. T. Currículo na Educação Infantil: diálogo com os demais elementos da Proposta Pedagógica. São Paulo: editora Scipione, 2012.

FONTES, R. S.; PLETSCH, M. D.; BRAUN, P.; GLAT, R. Estratégias pedagógicas para a inclusão de alunos com deficiência mental no ensino regular. In: GLAT, R. Educação Inclusiva: cultura e cotidiano escolar, Rio de Janeiro: 7letras, 2009.

GHIRALDELLI, P. Infância, educação e neoliberalismo. São Paulo: Cortez, 1996.

KRAMER, S. As crianças de 0 a 6 anos nas Políticas Educacionais no Brasil: Educação Infantil e/é Fundamental. Educação e Sociedade, Campinas, v. 27, n. 96, p. 797-818, 2006.

LIMA, E. A.; RIBEIRO, A. E. M.; VALIENGO, A. Criança, infância e Teoria HistóricoCultural: convite à reflexão. Revista teoria e prática da Educação, v. 15, n. 1, p. 67-77, 2012.

MIRANDA, M. J. C. et al. (org.). Inclusão, Educação Infantil e Formação de professores. Marília: Oficina Universitária, Unesp Publicações, 2013. 
OLIVEIRA, A. A. S. Adequações curriculares na área da Deficiência Intelectual: algumas reflexões. In: OLIVEIRA, A. A. S.; OMOTE, S.; GIROTO, C. R. M. Inclusão escolar: as contribuições da Educação Especial. Marília: Cultura acadêmica, Unesp Publicações, 2011.

OLIVEIRA, J. P.; ROCHA, A. N. D. C.; MIURA, R. K. K.; RODRIGUES, E. S.

Desenvolvimento Infantil, escola e inclusão: Ações Pedagógicas e Intersetoriais. Curitiba: CRV, 2017, 210 p.

VIANNA, H. M. Pesquisa em educação: a observação. Brasília: Plano Editora, 2003. 106p.

VYGOTSKY, L. S. Fundamentos da Defctologia - Obras Completas - tomo cinco. Cuba: Editorial Pueblo y Educacíon, 1997.

VYGOTSKY, L. S. A formação social da mente: o desenvolvimento dos processos psicológicos superiores. 5. ed. São Paulo: Martins Fontes, 1994, 89p.

\section{Como referenciar este artigo}

OLIVEIRA, Jáima Pinheiro.; ARAUJO, Mariane Andreuzzi. A participação de uma criança com síndrome de Down em práticas pedagógicas na Educação Infantil. Revista IberoAmericana de Estudos em Educação, Araraquara, v. 14, n. esp. 1, p. 869-882, abr., 2019. EISSN: 1982-5587. DOI: 10.21723/riaee.v14iesp.1.12212

Submetido em: 06/08/2018

Aprovado em: 21/09/2018 